\title{
Nickel and nickel oxide nanocrystals selectively grafting on multiwalled carbon nanotubes
}

\author{
Yendrapati Taraka Prabhu ${ }^{1 *}$, Kalagadda Venkateswara Rao ${ }^{1}$, Bandla Siva Kumari ${ }^{2}$, Vemula Sesha Sai ${ }^{1}$ and Tambur Pavani ${ }^{1}$
}

\begin{abstract}
Nickel and nickel oxide nanocrystals in their pure phase are carefully embellished by a facial method on oxygen-functionalized multi-walled carbon nanotubes (O-MWCNTs) using nickel nitrate (NN) was effectively accomplished for the first time by calcining them in hydrogen, nitrogen and air, respectively, at suitable temperatures. Nickel and nickel oxide nanocrystals impregnated O-MWCNTs were examined for its structure and morphology by various techniques, such as powder $X$-ray diffraction, Fourier transform infrared spectroscopy, transmission electron microscopy and field emission scanning electron microscopy. The nanocrystals on the O-MWCNTs were determined of 15-20 nm size. Decorated nanocrystals on CNT's have potential applications in semiconductor industries.
\end{abstract}

Keywords: MWCNTs; Nickel Nitrate; TEM; XRD; FTIR

\section{Background}

In the field of nanoscience and nanotechnology carbon nanotubes (CNTs) are the most wanted materials due to their extraordinary properties and potential applications as step forward materials for catalysis, composite reinforcement materials, microelectronics, energy storage, chemical sensors, etc. [1,2]. Mechanical stiffness, field emission properties, excellent thermal and electrical conductivity, high aspect ratio, and the cavities of CNTs fetches them the advantage in their applications [3-6]. CNTs are chemically inert and insoluble in the most solvents thus hampering their application and manipulation in various possible fields. Surface functionalization of CNTs is one way of overcoming these difficulties. This method has established a wide range of applications in the fields of composite materials, sensors and catalysis [7-10].

By the application of oxidation reagents like $\mathrm{HNO}_{3}$ or a mixture of $\mathrm{H}_{2} \mathrm{SO}_{4} / \mathrm{HNO}_{3}$ can disjoint the aromatic ring system of CNTs [11]. As a result carboxylic $(-\mathrm{COOH})$, carbonyl $(-\mathrm{CO})$ and hydroxylic $(-\mathrm{OH})$ can be present on the nanotubes as they are required to anchor guest species such as metal ions to the CNT

\footnotetext{
* Correspondence: ytprabhusj@gmail.com

${ }^{1}$ Centre for Nano Science and Technology, Institute of Science and Technology, Jawaharlal Nehru Technological University Hyderabad, Telangana, India

Full list of author information is available at the end of the article
}

$[12,13]$. The wetting characteristics and reactivity of nanotubes are modified thus enriching their properties. It guides us to the subject of interfacial bonding between the metal atoms and defective and oxidized CNTs to ensure excellent mechanical performances for the CNT-reinforced metal-matrix composites.

The stable CNT-metal structures are potential engineering materials in the areas of CNT devices for different spintronics applications and CNT metal-matrix composites [14-16]. In much energy related applications like fuel cells, super capacitors, rechargeable batteries and hydrogen production Ni/CNT nanocomposites have been considered [17-19]. Production of metal/metal oxide and CNT composites were attempted by many but no uniform coating of CNTs were obtained. However some worked with polymers to assist the process of decorating of metal/metal oxides [20,21]. For example, Tang et al. [20] reported that Ni decorated MWCNTs were modified with poly (acrylic acid) for hydrogenation of $\alpha$, $\beta$-unsaturated aldehyde. Similarly homogeneous electro-deposition of $\mathrm{Ni}$ nanoparticles on 4-nitroaniline radical monolayer grafted on MWCNT was reported by Jin et al. [21]. There have been reports of utilizing stringent conditions such as electrophoretic deposition [22], hydrothermal [23], solvothermal [24], chemical vapor deposition [25], microwave 


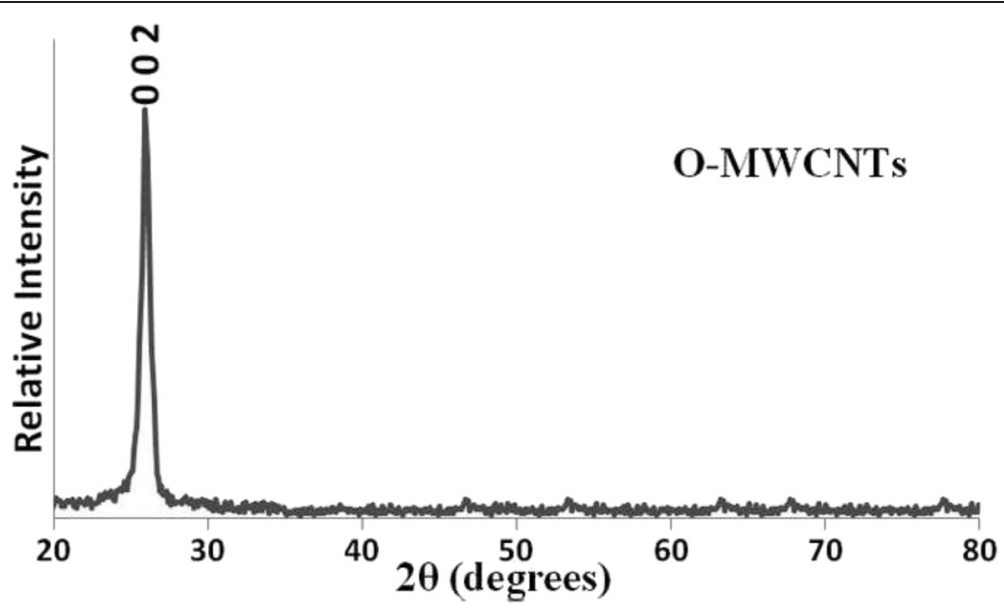

Figure 1 XRD patterns of O-MWCNTs.

irradiation [26], etc. for the uniform decoration of metal/ metal oxides on CNTs.

CNT based composites with metal/metal oxides like $\mathrm{Ni} / \mathrm{NiO}$ have potential applications. Fabrication of new powdery metal MWCNT composites could be done very easily thus expanding the horizons of its applications such as sensors and catalysis. A promising potential application has been revealed the improved hardness, excellent solid lubrication, protection against corrosion, catalytic performance [27-32]. This is one of most few methods that could produce fast and firm MWCNTs decorated with metal and metal oxides. We provide an easy and fitting method for the preparation of nickel and nickel oxide nanoparticles well and uniform dispersion on MWCNTs. Grafting the external surface of MWCNTs with metal and metal oxide nanoparticles of nickel we establish an innovative and a low cost alternative route. For the first time nickel nitrate was used as precursor to decorate on MWCNTs. The weight percentage ratio of nickel nitrate to $\mathrm{CNTs}$, reaction temperature, impregnation time and atmosphere are selectively restricted to obtain the particle size and homogeneous distribution of nickel and nickel oxide particles on CNTs.

\section{Methods}

\subsection{Oxidation of MWCNTs}

Oxygen functionalized MWCNTs were produced by the treatment of MWCNTs with the mixture of concentrated $\mathrm{H}_{2} \mathrm{SO}_{4}$ and $\mathrm{HNO}_{3}$ with the molar ratio of $3: 1$ $[17,18] .75 \mathrm{ml}$ of $\mathrm{H}_{2} \mathrm{SO}_{4}(97 \%)$ and $25 \mathrm{ml}$ of conc. $\mathrm{HNO}_{3}$ (65\%) were carefully mixed together and added to $1 \mathrm{gm}$. of MWCNTs in a round bottomed flask. It was heated under constant stirring at $50^{\circ} \mathrm{C}$ for $8 \mathrm{hrs}$. Then it was allowed to cool to room temperature. Then an equal amount of deionized water was added. Now the whole solution was filtered. The residue was washed 3-4 times with deionized water and deionized water is added till neutral $\mathrm{pH}$ was attained. The residue is dried. The oxygen functionalized MWCNTs were obtained.

\subsection{Grafting of nickel nitrate on O-MWCNTs}

Now $100 \mathrm{mg}$ of O-MWCNTs were taken and added in $50 \mathrm{ml}$ of toluene and ultra sonicated till good suspension and dispersion was obtained. In another beaker $77.2 \mathrm{mg}$ of Nickel Nitrate (15 wt\% of $\mathrm{Ni}$ ) was suspended in $30 \mathrm{ml}$ of toluene for $5 \mathrm{~min}$. Now Nickel Nitrate solution was added to the oxygen functionalized MWCNTs toluene solution and kept under stirring for $4 \mathrm{hrs}$. The whole solution was allowed to be cooled to room temperature and then filtered, washed with acetone. Nickel nitrate decorated MWCNTs are obtained. The obtained powder $20 \mathrm{mg}$ of Nickel

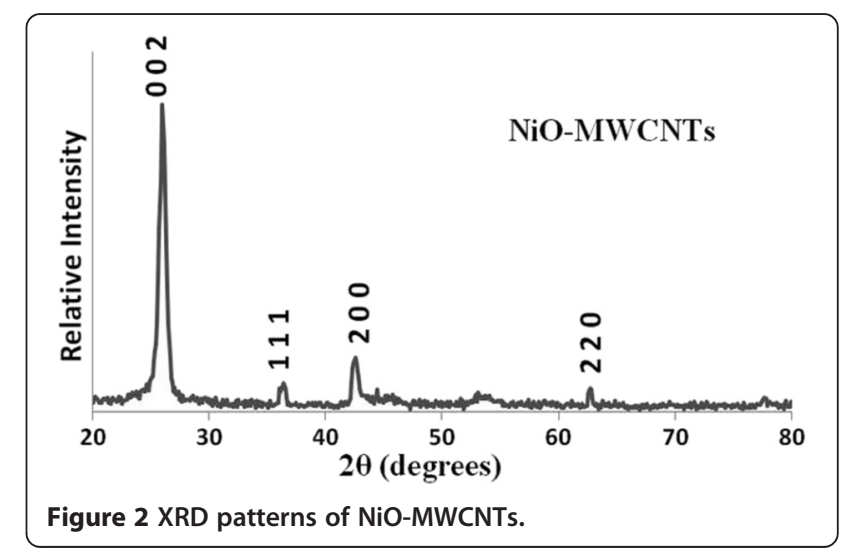




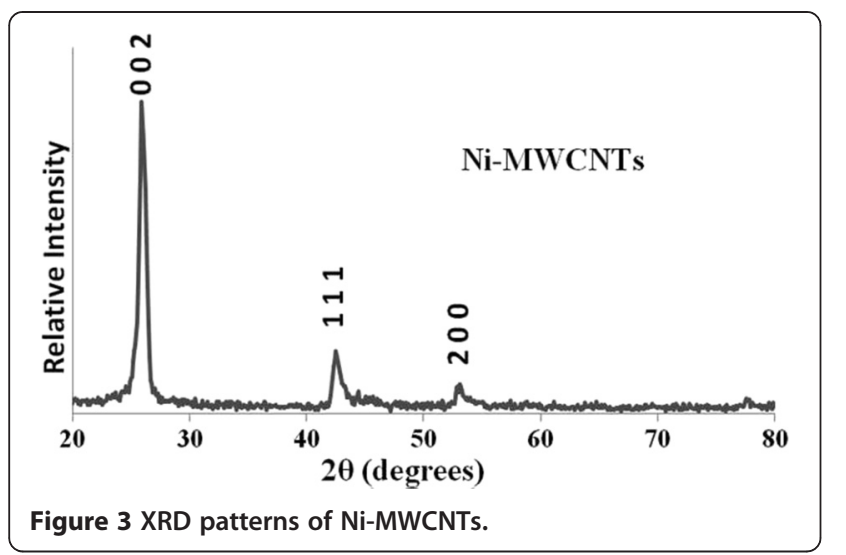

Nitrate MWCNTs is placed in quartz tube and heated at the desired temperatures $300^{\circ} \mathrm{C}$ for $1 \mathrm{~h}$ under a continuous flow of air. It was dried at room temperature.

\subsection{Calcination of Nickel Nitrate decorated MWCNTs}

In a tubular furnace equipped with quartz tube Nickel nitrate MWCNTs were calcinated. Nickel Nitrate MWCNTs were divided into two parts. One part $20 \mathrm{mg}$ of Nickel nitrate MWCNTs were calcined at $400^{\circ} \mathrm{C}$ for $1 \mathrm{hr}$. under continuous flow of hydrogen at a flow rate of $300 \mu \mathrm{L}$ per min and another part were calcined for $3 \mathrm{hr}$. under continuous flow of nitrogen at a flow rate of $300 \mu \mathrm{L}$ per min.

\subsection{Glossary}

CNTs (Carbon Nano Tubes), MWCNTs (Multi walled Carbon Nano Tubes), O-MWCNTs (oxygen functionalized Multi walled Carbon Nano Tubes), NNMWCNTs (Nickel Nitrate Multi walled Carbon Nano Tubes), FTIR (Fourier Transform Infrared Spectroscopy), SEM (Scanning Electron Microscope) and TEM (Transmission Electron Microscope).

\section{Results and discussions}

In the Figures 1,2 and 3 the XRD pattern $\mathrm{O}$ MWCNTs, NN-MWCNTs along with the calcined products of NN MWCNTs in hydrogen and Nitrogen atmosphere are shown. Two distinct diffraction peaks for graphitic structure at $2 \theta=26^{\circ}$ and $43^{\circ}$ corresponding to the $h k l$ reflections (002) and (100), respectively are displayed by the O-MWCNTs [33]. These peaks indicate that the graphite is intact even after the treatment with acids. There is no change in the XRD pattern for the NN impregnated MWCNTs may be due to the amorphous nature of the impregnated $\mathrm{NN}$. $\mathrm{NiO}$ nanocrystals have three distinct peaks at $2 \theta=$ $36.9^{\circ} 42.8^{\circ}$ and $62.3^{\circ}$ corrosponding to (111), (200) and (220) $h k l$ planes on the surface of MWCNTs in the $\mathrm{NiO}-\mathrm{MWCNT}$ which are formed in the presence of nitrogen at $400^{\circ} \mathrm{C}$ [21]. Pure Nickel phase if formed on the surface of MWCNTs when it is treated with hydrogen at $400 \mathrm{cC}$ and the $h k l$ reflections are (111) and $(200)$ at $2 \theta=44.2^{\circ}$ and $51.7^{\circ}$ [21]. There are no

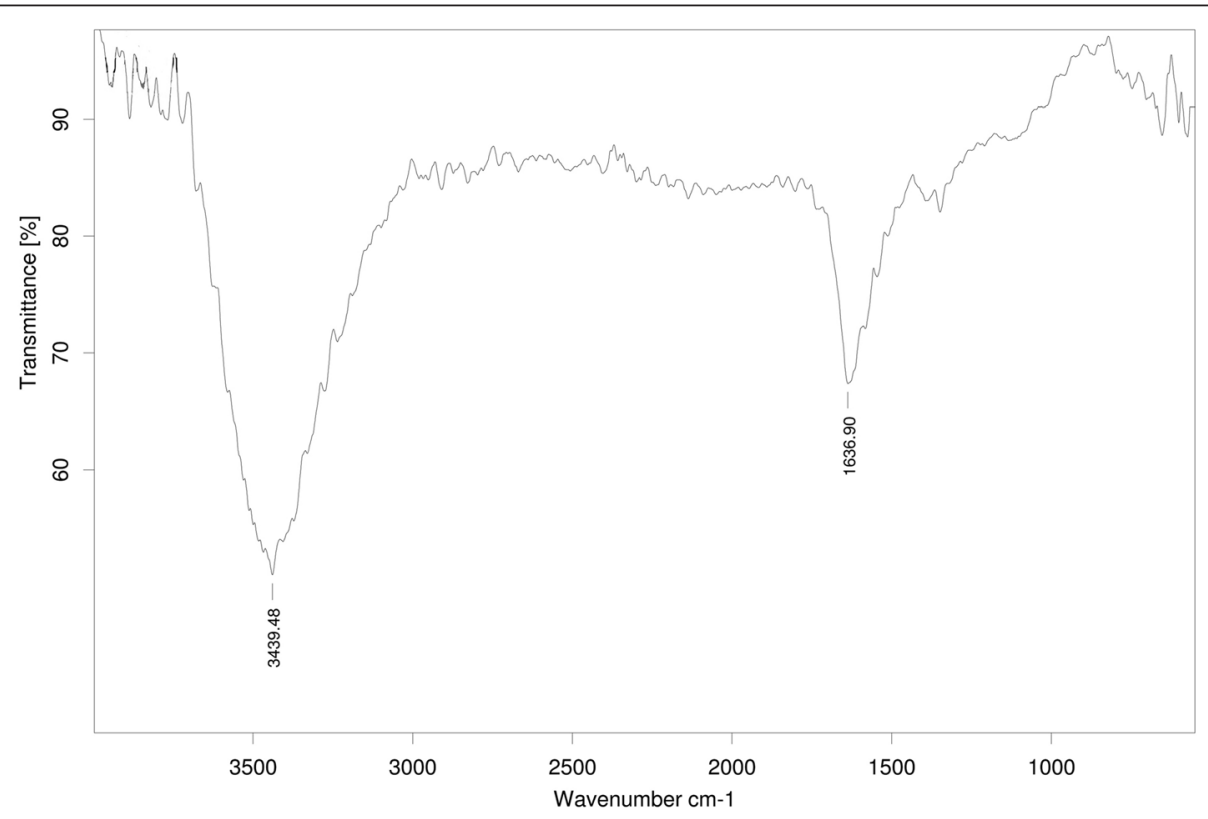

Figure 4 FTIR spectra of O-MWCNTs. 


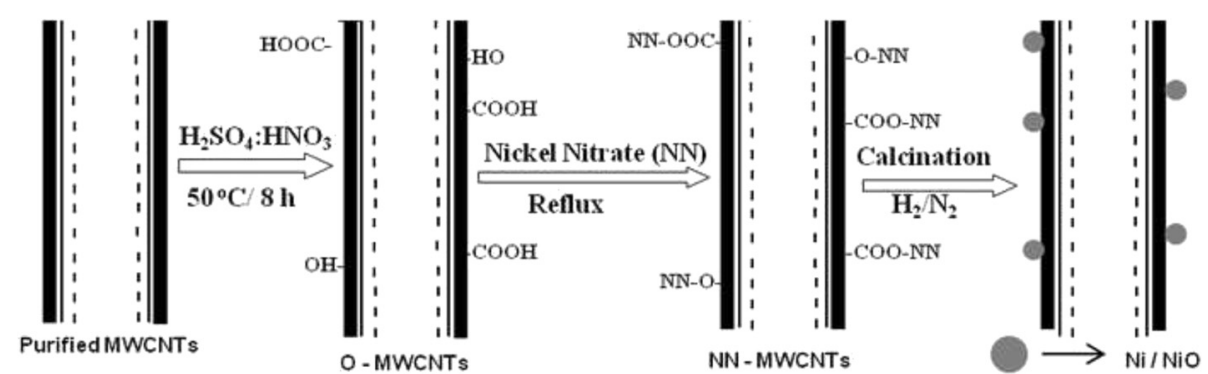

Figure 5 Schematic illustration of the various steps involved to obtain the final products.

other peaks other than nickel indicating the purity of the composite formation.

The active site of oxygen functionalized MWCNTs which were anchored by Nickel and Nickel Oxide Nanoparticles were investigated by FTIR which were shown in the Figure 4 . O-H stretching frequency originating by the absorption of water molecules on the
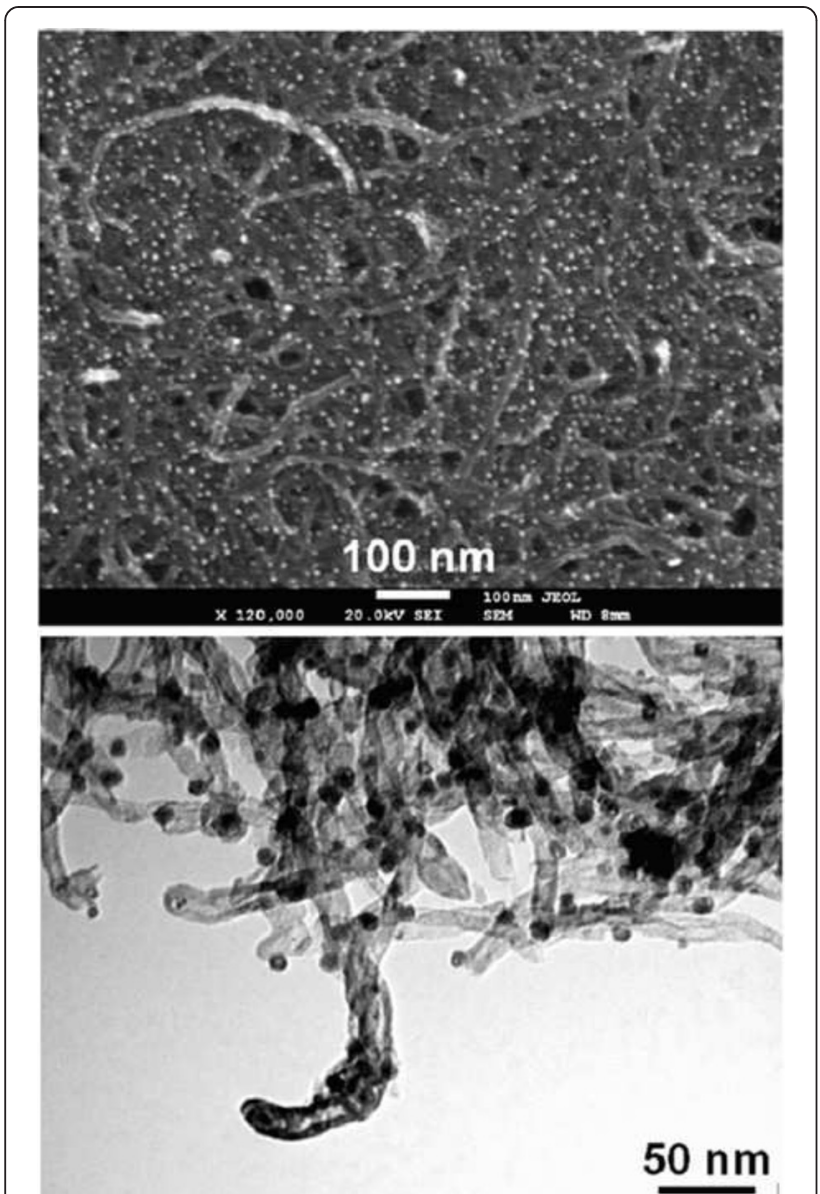

Figure 6 FEG-SEM image of Ni-MWCNTs and TEM image of Ni-MWCNTs. amorphous carbon in the CNTs [34] can be ascribed to the peak around $3439 \mathrm{~cm}^{-1} . \mathrm{C}=\mathrm{C}$ stretching frequency is assigned to the two peaks $1636 \mathrm{~cm}^{-1}$.

In a schematic representation the mechanism of nickel and nickel oxide decoration of CNTs is explained in the Figure 5. Nickel nitrate is impregnated using hydrogen and nitrogen atmosphere in toluene solvent. CNT is decorated with the help of nickel nitrate. The functional groups like $\mathrm{COOH},-\mathrm{OH}$ and $\mathrm{C}=\mathrm{C}$ are created from CNTs by treating it with sulfuric and nitric acid mixture. These groups act as active sites for metal cations to cling to $\mathrm{CNTs}$ in suitable temperatures.

The structure of MWNCT can be known to be undamaged by conducting FEG-SEM and TEM and thus analyzing the morphology of composites. Nickel nanocrystals can be uniformly spread over the outer surface of MWCNTs at $400^{\circ} \mathrm{C}$ in the presence of hydrogen by the help of the above stated method and hence forms Ni-MWCNTs (Figure 6).

\section{Conclusion}

A new method for the synthesis of nickel and nickel oxide nanoparticles are decorated on MWCNTs using nickel nitrate for the first time. By calcinations at suitable temperatures and atmosphere the metal and metal oxide carbon nanocomposites were synthesized using Nickel Nitrate. On the surface of MWCNTs nickel and nickel oxide are homogeneously dispersed and the particle size was found to be $10-20 \mathrm{~nm}$. Both the decorated nanocrystals on CNTs have potential applications in heterogeneous catalysis and semiconductor industries.

Competing interests

The authors declare that they have no competing interests.

Author's contributions

The authors YTP and KVR have done the experimental part. The authors BSK and TP have done the functionalization of MWCNTs. The authors YTP and VSS have done analysis part of the work. All authors read and approved the final manuscript. 


\section{Author details}

${ }^{1}$ Centre for Nano Science and Technology, Institute of Science and Technology, Jawaharlal Nehru Technological University Hyderabad, Telangana, India. ${ }^{2}$ Department of Botany, Andhra Loyola College, Vijayawada, Andhra Pradesh, India.

Received: 27 July 2014 Accepted: 28 October 2014

Published online: 12 January 2015

\section{References}

1. PJF Harris, Carbon nanotube science (Cambridge University Press, Cambridge, 2009)

2. S ljima, Phys. B 323, 1 (2002)

3. RS Ruoff, D Qian, WK Liu, CR Physique 4, 993 (2003)

4. R Avouris, Chem Phys 281, 429 (2002)

5. M Endo, T Hayashi, YA Kim, M Terrones, MS Dresselhaus, Phil Trans Roy Soc Lond A 362, 2223 (2004)

6. RH Baughman, AA Zakhidov, WA de Heer, Science 297, 787 (2002)

7. M Olek, M Hilgendorf, M Giersig, Colloids Surf., A 292, 83 (2007)

8. S Kundu, Y Wang, W Xia, M Muhler, J Phys Chem C 112, 16869 (2008)

9. NT Hung, IV Anoshkin, AP Dementjev, DV Katorov, EG Rakov, Inorg. Mater. $44,219(2008)$

10. C Wang, G Zhou, H Liu, J Wu, Y Qiu, BL Gu, W Duan, J Phys Chem B 110 10266 (2006)

11. W Linert, I Lukovits, J ChemInf Model 47, 887 (2007)

12. V Datsyuk, M Kalyva, K Papagelis, J Parthenios, D Tasis, A Siokou, I Kallitsis, C Galiotis, Carbon 46, 833 (2008)

13. G Zhang, S Sun, D Yang, JP Dodelet, E Sacher, Carbon 46, 196 (2008)

14. E Unger, GS Duesberg, M Liebau, AP Graham, R Seidel, F Kreupl, W Hoenlein, Appl.Phys.A 77, 735 (2003)

15. XH Chen, CS Chen, HN Xiao, HB Liu, LP Zhou, SL Li, G Zhang, Tribol. Int. 39, 22 (2006)

16. J Cheng, X Zhang, Y Ye, J. Solid State Chem. 179, 91 (2006)

17. JC De Jesus, I Gonza' lez, A Quevedo, T Puerta, J. Mol. Catal. A 228, 283 (2005)

18. KY Lin, WT Tsai, JK Chang, J Int, Hydrogen Energy. J. Int 35, 7555 (2010)

19. CT Hsieh, YW Chou, WY Chen, J. Solid State Electrochem. 12, 663 (2008)

20. Y Tang, D Yang, F Qin, J Hu, C Wang, H Xu, J. Solid State Chem. 182, 2279 (2009)

21. GP Jin, YF Ding, PP Zheng, J. Power Sources 166, 80 (2007)

22. SV Mahajan, J Cho, MSP Shaffer, AR Boccaccini, JH Dickerson, J. Eur. Ceram. Soc. 30, 1145 (2010)

23. M Jayalakshmi, MM Rao, N Venugopal, KB Kim, J. Power Sources 166, 578 (2007)

24. A Oki, L Adams, Z Luo, Inorg. Chem. Commun. 11, 275 (2008)

25. MKS Li, P Gao, P-L Yue, X Hu, Sep.Purif.Technol 67, 238 (2009)

26. J Yan, Z Fan, T Wei, J Cheng, B Shao, K Wang, L Song, M Zhang, J. Power Sources 194, 1202 (2009)

27. WX Chen, JP Tu, LY Wang, HY Gan, ZD Xu, XB Zhing, Carbon 41, 215 (2003)

28. Y Sun, J Sun, M Liu, Q Chen, Nanotechnology 18, 505704 (2007)

29. S Arai, A Fujimori, M Murai, M Endo, Mater. Lett. 62, 3545 (2008)

30. XH Chen, CS Chen, HN Xiao, FQ Cheng, G Zhang, GJ Yi, Surf. Coat. Technol. 191, $351(2005)$

31. Z Yang, H Xu, Y-L Shi, M-K Li, Y Huang, H-L Li, Mater. Res. Bull. 40, 1001 (2005)

32. X Zhang, W Jiang, D Song, J Liu, F Li, Mater. Lett. 62, 2343 (2008)

33. F Liu, XB Zhang, D Haussler, W Jager, GF Yi, JP Cheng, XY Tao, ZQ Luo, SM Zhou, J. Mater. Sci. 41, 4523 (2006)

34. E Titus, N Ali, G Cabral, J Gracio, PR Babu, MJ Jackson, J. Mater. Eng. Perform. $15,182(2006)$

\section{Submit your manuscript to a SpringerOpen ${ }^{\odot}$ journal and benefit from:}

- Convenient online submission

- Rigorous peer review

- Immediate publication on acceptance

- Open access: articles freely available online

- High visibility within the field

- Retaining the copyright to your article

Submit your next manuscript at $>$ springeropen.com 